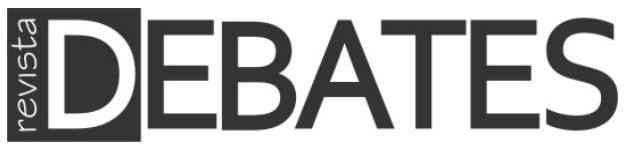

\title{
Sobre a identidade do capital social e o capital social da identidade
}

\author{
On the identity of social capital and the social capital of identity
}

\section{Asimina Christoforou}

\section{Resumo}

$\mathrm{Na}$ economia contemporânea, o capital social é identificado por alguns como normas e redes que enfatizam confiança, reciprocidade e cooperação para a produção de bens públicos. Mas os críticos clamam que o capital social é, principalmente, de origem individualista e fornece terra firme para subordinação do trabalho do capital. Argumentamos que, apesar dos maus-tratamentos neoclássicos, concepçóes mais socializadas do capital social conferem aos indivíduos capacidade de compartilhar um senso de obrigação social e identidade comum e buscar estratégias articuladas para o bem-estar público. Tentamos reintegrar o "social" ao capital social através do conceito de encapsulamento social, onde os indivíduos se engajam livremente em processos de reflexão, mobilização social e debate político para assessorar conflitos diferentes e frequentes, e objetivos que atravessam múltiplas agências coletivas. Assim, as escolhas dependem não apenas de utilidade pessoal, mas também de identidade pessoal, como, por exemplo, que tipo de pessoa alguém quer ser e que tipo de sociedade alguém deseja ter.

\section{Palavras-chave}

Capital Social; Encapsulamento Social; Identidade; Teoria Neoclássica.

\begin{abstract}
In contemporary economics, social capital is identified by some with norms and networks that enhance trust, reciprocity and cooperation for the production of public goods. But critics claim that social capital is principally of individualist origin and provides solid ground for the subordination of labour by capital. We argue that, despite neoclassical (mis)treatments, more socialised conceptions of social capital address individuals' capacities to share a sense of social obligation and common identity and pursue joint strategies for public welfare. We attempt to reinstate the 'social' in social capital via the concept of social embeddedness, where individuals freely engage in processes of reflection, social mobilisation and political debate to assess different and often conflicting values and objectives across multiple collective agencies. Choices thus depend not only on personal utility, but also on personal identity, i.e. what kind of person one wants to be and what kind of society one wishes to have.
\end{abstract}

\section{Keywords}

Social Capital; Social Embeddedness; Identity; Neoclassical Theory. 


\section{Introdução}

Capital social, em seu sentido contemporâneo, se identifica com normas e redes de cooperação, reciprocidade e confiança que facilitam a ação coletiva para o alcance do benefício mútuo. Inicialmente, esse conceito apareceu nas disciplinas de ciências sociais fora da economia, mas logo ganhou apelo generalizado entre economistas em suas tentativas de explicar o comportamento cooperativo. No final do século XX, alguns economistas usaram o conceito de capital social para representar um conjunto de recursos sociais produtivos, nos quais os indivíduos investem para apoiar atividades coletivas de esfera não econômica e, assim, produzir os bens públicos que enaltecem o bem-estar e o desenvolvimento. Entretanto, outros ofereceram visóes críticas do conceito de capital social e argumentaram que o princípio neoclássico de racionalidade tem mantido dominância dentro da economia e para além das ciências sociais. Dessa maneira, as análises sobre o capital social tendem a desconsiderar o conteúdo coletivo e o contexto da interaçáo humana e a descartar percepçóes mais radicais das relaçóes sociais. Em virtude do princípio da maximização da utilidade, normas e redes são reduzidas a meios exogenamente determinados, através dos quais os indivíduos, em última análise, servem a benefícios privados. Dessa maneira, críticos reivindicam que, apesar de o conceito de capital social ter sido aplicado para enfatizar aspectos de açáo coletiva e bem-estar, ele proporcionou aos economistas em instituiçóes poderosas, como o Banco Mundial, os meios para promover sua agenda neoliberal.

Neste artigo, concordamos que os (des)tratamentos neoclássicos do capital social fornecem interpretaçôes individualistas e reducionistas do comportamento humano. Não obstante, argumentamos que o conceito de capital social é útil ao destacar aspectos políticos e sociais de agência humana, particularmente a capacidade dos indivíduos para oferecer a um público mais amplo benefícios do bem-estar social, com base em um senso de obrigação social e identidade compartilhada. De fato, um histórico conceitual que remete ao século XVIII revela visóes mais socializadas sobre o capital social, que desafiam os dogmas da principal corrente econômica e confrontam as consequências negativas do capitalismo. Isso pode criar a oportunidade para redefinir conceitos e metodologias, e reintegrar a identidade social do capital social em resposta a uma ciência e sociedade em constante mudança, e um esforço e diálogo duradouros para promover conhecimento e bem-estar. Com esse fim, exploramos princípios alternativos de comportamento racional baseados no conceito de enraizamento social. Indivíduos socialmente enraizados ao mesmo tempo moldam e são moldados pela sociedade na determinaçáo do tipo de pessoa que desejam ser e do tipo de sociedade almejam ter. Eles se identificam com múltiplas agências coletivas, 
caracterizadas por valores e objetivos diferentes, que estão frequentemente em conflito, e se engajam livremente em um processo reflexivo para avaliar esses valores e objetivos através de mecanismos de mobilização social e debate político.

Portanto, a principal contribuição deste artigo é abrir uma discussão atravessando disciplinas e desenvolvendo as possibilidades acadêmicas para uma concepção alternativa de capital social que incorpore noçóes de enraizamento e substitua visóes reducionistas de "social" e de "capital". Partimos de visões mais socializadas de capital social, desenvolvidas historicamente, mas que têm sido desconsideradas devido à crescente influência de abordagens econômicas dominantes. Iniciamos mapeando a identidade do capital social e discutindo brevemente as implicaçôes dos pressupostos neoclássicos. Enriquecemos nossa análise examinando abordagens mais socializadas ou socialistas do capital social na Seção "Capital social de uma perspectiva 'socializada' ou 'socialista". Então, na Seção "Restaurando o "social" em capital social", tentamos restabelecer o "social" no capital social ao explorar tratamentos alternativos não neoclássicos de interação humana, baseados em noçóes de enraizamento social e identidade pessoal. Finalmente, fazemos algumas consideraçôes conclusivas.

\section{(Des)tratamentos neoclássicos do capital social}

A "abordagem econômica" do capital social aparece na obra de Becker (1974 e 1996) e Glaeser et al. (1999 e 2002). Em síntese, ambos apelam a um modelo econômico de investimento para explicar a criaçáo do capital social, similar a molduras teóricas aplicadas tradicionalmente à acumulação de capital físico e humano. Becker explicitamente expressa a visão de que o modelo econômico de maximização de utilidade pode ser aplicado para explicar e predizer todas as facetas do comportamento econômico e não econômico (cultural, biológico e psicológico), em qualquer hora e em qualquer lugar (BECKER, 1996). Glaeser e seus colegas também concluem que o capital social pode ser estudado com as ferramentas da teoria do preço. Eles reivindicam que, a distinção entre comportamentos sociais baseados em preferência ou incentivo, além de ser difícil de fazer, também é imaterial, visto que, ultimamente, o importante as redes criarem resultados cooperativos e socialmente eficientes (GLAESER et al., 1999; GLAESER et al., 2002).

Essa abordagem se torna problemática uma vez que falha em capturar aspectos profundos do comportamento humano, como o senso de identidade compartilhada (classe, gênero, raça e etnicismo) e compromisso com valores sociais (equidade, reciprocidade e lealdade), os quais derivam de processos agregados de participação social e política. Além disso, em vez do reconhecimento do enraizamento 
do comportamento econômico e troca nos relacionamentos sociais e instituiçóes, o modelo econômico implica que as relaçôes sociais estejam enraizadas no sistema econômico. Os que adotam um ponto de vista mais radical conclamam que, a princípio, o capital social é individualista e presume um conceito não histórico e não social do comportamento humano. Por exemplo, Fine (2010) aponta que, mesmo em abordagens mais aprimoradas, uma característica da análise de Becker que tende a sobreviver entre economistas e teóricos sociais é a tentativa de incorporar fatores sociais e econômicos mais amplos, enquanto retém o uso acrítico de conceitos prevalecentes e técnicas consoantes com a razão econômica ortodoxa. Juntamente com os termos 'globalizaçáo', 'economia baseada em conhecimento' 'cultura organizacional' e 'flexibilidade', capital social é considerado como sendo um veículo para a promoção histórica e social da agenda política e ideológica das classes dominantes, empresários, acadêmicos, organizaçôes internacionais e legisladores. Isso obscurece a distinção entre o "social" e o "capital" de tal maneira que concilia e preserva o sistema de capitais que oferece terra firme para a exploraçáo do trabalho.

Smith e Kulynych (2002) também argumentam que "capital" é, essencialmente, um conceito com significados monetários e contábeis associados com o capitalismo, um sistema econômico no qual individualismo, competição e riqueza têm um papel significativo, e a distribuição de recursos determina relaçóes de poder e a subordinação do trabalho aos capitalistas. Mediante a identificação das capacidades sociais dos indivíduos como "capital", incentivos econômicos e objetivos subjacentes estreitamente definidos parecem naturais, inevitáveis e legítimos. Esse é o resultado do desenvolvimento intelectual, social, econômico e político que ocorreu no final do século XX e estáo relacionados com o imperialismo econômico e a "despolitização" da política, gerando uma valorização do capital. Em geral, o imperialismo econômico está associado com o uso de métodos e conceitos com raízes na economia neoclássica para entender uma gama extensa de relaçóes políticas e sociais. "Despolitização" está ligada à burocratização e racionalização do estado e da sociedade, onde a eficiência se torna o valor político primário, substituindo discussóes de justiça social e bem-estar. Desse modo, o processo de decisão pública se torna um problema técnico, divorciado da controvérsia substantiva sobre os fins da política e os cidadãos são vistos como consumidores que maximizam a utilidade para avaliar o desempenho de seus governos com base no fornecimento de bens materiais, em vez de quão bem isso preenche uma responsabilidade social para redistribuição e equidade (SMITH e KULYNYCH, 2002). Argumenta-se que o capital social tem servido como um conduto para que a economia incorpore o "social" sem o "político" (ver também FINE, 2001 e 2010; HARRISS, 2002). 
De acordo alguns autores, o fator que colocou capital social no mapa intelectual e em agendas de políticas públicas ao redor do globo durante esse período foi, inesperadamente, o Banco Mundial (FINE, 1999, 2001, 2002 e 2010; HARRISS, 2002; SMITH e KUNYLYCH, 2002; SCHUURMAN, 2003: FINE e LAPAVITSAS, 2004). O Banco Mundial introduziu o capital social como fator concomitante ao consenso Pós-Washington, e o usou como uma ferramenta adicional para erradicar a pobreza e enaltecer o desenvolvimento dos países de Terceiro Mundo, ao promover e financiar participaçôes em associaçôes populares, redes autogovernadas, organizaçóes não governamentais e projetos comunitários. Um grupo de teóricos sociais no Banco viram o conceito de capital social como uma oportunidade de persuadir economistas a levarem mais a sério o social no desenvolvimento de teorias e políticas (BEBBINGTON et al., 2006). Para Fine (2010), isso foi uma estratégia destinada a falhar, pois ficou comprometida pelos economistas do Banco Mundial, que apoiaram o neoliberalismo e a nova microeconomia refletida no consenso pós-Washington, e que via o capital social como meio de retificar imperfeiçóes de mercado, derivadas de assimetrias de informação e custos de transaçóes. Isso teve sérias implicaçóes políticas. Primeiro, intervençóes redistributivas do governo seriam substituídas por iniciativas privadas que enalteciam a eficiência na forma de redes sociais não políticas, associaçóes locais e grupos comunitários de autoajuda. Segundo, os que foram privados dessas intervençôes seriam os que ficariam como responsáveis pelos problemas de subdesenvolvimento, porque eles não teriam o tipo "certo" de capital social. Por fim, organizaçôes internacionais foram "equipadas" com a retórica para apoiar quaisquer grupos sociais que considerassem capazes de contribuir para servir suas estreitas agendas. Portanto, como afirma Fine, a única coisa que os proponentes do Banco Mundial conquistaram foi legitimar um conceito inadequado de economia para subordinar o "social" ao privado e ao lucrativo, e para servir os interesses institucionais internos e externos da organização estreitamente definidos (FINE, 2010).

Entretanto, o Banco Mundial não é a única instituição ou agente com uma ideia do que é o capital social e como ele afeta o desenvolvimento. Existiram visões alternativas que desafiaram o Consenso Pós-Washington e seus fundamentos teóricos. Por exemplo, alguns acreditam que o apelo do Capital Social no final do século XX coincidiu com uma desilusão tanto pelos regimes liberais orientados pelo mercado do Ocidente, quanto pelos regimes comunistas centralmente planejados do Leste que falharam em assegurar a paz mundial, o desenvolvimento econômico e o bem-estar social. De fato, Bowles e Gintis argumentam que, conforme o século foi se 
aproximando do fim, o capital social atraiu pensadores e praticantes de uma vasta gama de fundos ideológicos, desencantados com utopias tanto de Esquerda como de Direita, que acreditavam que as falhas do mercado e a ineficácia do governo poderiam ser resolvidas ao enaltecer normas e redes de confiança, associação e ação coletiva (BOWLES e GINTIS, 2002). Evans sugere que o capital social está associado com formas de relaçóes sinergéticas e redes que abarcam a divisão público-privada, e como tal se adequa tanto à lógica do desenvolvimento do mercado quanto á lógica das teorias tradicionais de administração pública (EVANS, 1996a). Hyden também aponta que, durante o mesmo período, o discurso de desenvolvimento incorporou conceitos de capital social e sociedade civil dentre as novas perspectivas colocadas por tendências intelectuais focadas no que é, genericamente, referido como "cultura política" (HYDEN, 1997). Essas tendências atribuem um papel distinto à agência humana e participação democrática e diferem da teoria neoliberal da "escolha racional", uma vez que reconhecem a influência de instituiçóes na escolha humana. Schuurman (2003) argumenta que o capital social pode proporcionar descobertas valiosas em relação ao desenvolvimento de novas formas de política e governança global, onde o papel de organizaçóes da sociedade civil e partes interessadas da sociedade não estariam limitadas a uma estratégia anti-hegemônica, mas também agiriam para reconectar o social ao político.

Para Fine, o conceito de capital social de fato se ajusta em uma reaçáo crescente tanto do estativo excessivo quanto do excessivo neoliberalismo, no entanto náo se aadapta com a política adversaria e se situa fora do contexto mais amplo das relaçóes de poder. $\mathrm{O}$ capital social é habitualmente ligado a redes sociais que produzem resultados econômicos e políticos positivos, independente do contexto mais amplo dentro do qual ele está situado. Consequentemente, ele se torna útil para uma perda das formas tradicionais das lutas antiautoritárias e, ultimamente, ele apoia formas liberalistas de concessão (FINE, 2010). Putnam exerceu profunda influência no que diz respeito a formas liberalistas de concessão, adotando uma abrangência neo-tocqueviliana, cujos altos níveis de engajamento cívico estáo conectados a mais envolvimentos políticos e a democracia, com uma limitada referência ao impacto das condiçôes da repressáo política, do estresse econômico, do intenso conflito social e da hegemonia cultural que pode obrigar grupos a se engajarem em açóes defensivas e ofensivas para resistirem e restaurarem estabilidade e democracia (EDWARDS e FOLEY, 1998). Putnam se inspira no trabalho de Coleman, que adota uma perspectiva de escolha racional nas relaçóes sociais (PUTNAM, 1993). No entanto, contrário a Putnam, Colemam vê o capital social como um estoque relacional de recursos disponíveis exclusivamente aos membros do grupo para maximizar seu bem- 
estar, o qual não coincide, necessariamente, com o do público em geral. Loury (1977 e 1987) está particularmente interessado na distribuição desigual de recursos materiais e sociais entre os indivíduos, e aponta o fato de a segregaçáo social da família e das conexôes comunitárias, baseadas em raça, etnicismo e classe, poderem afetar adversamente o acesso individual à saúde, educação e renda.

Bourdieu, um crítico teórico, produz uma abordagem mais radical, no qual o capital social se identifica com recursos individuais conseguidos através de seus laços sociais para assegurar um status social e privilégios e para sustentar estruturas vigentes de classe e poder. Ele conecta o capital social a uma

\begin{abstract}
Posse de uma rede duradoura de relaçóes mais ou menos institucionalizadas de mútuo conhecimento e reconhecimento [...] o que fornece a cada um de seus membros com o fundo de um capital de posse coletiva, uma "credencial" que os dá direito ao crédito, nos diversos sentidos da palavra (no domínio econômico, social e cultural) (BOURDIEU, p. 249-250).
\end{abstract}

Os intercâmbios sociais geralmente são recíprocos com aqueles que possuem um mesmo status social e exploradores com aqueles de status diferentes, portanto, sustenta estruturas de distribuição desigual de recursos econômicos e sociais entre os indivíduos. Contrário a Putnam e Coleman, Bourdieu coloca ênfase considerável nas dimensôes de fatores contextuais de poder, de tal forma que o capital social é entendido como um constructo social que desempenha um papel na reproduçáo e na transformação dominantes econômicas e sociais (BOURDIEU, 1986; FINE, 2001 e 2002, 2010; SMITH e KULYNYCH, 2002). Fine (2001) cita uma série de estudos de casos nos quais as estruturas hierárquicas sociais apoiam relaçōes sinergéticas transversalmente à divisão público-privada que reforçaram relaçóes com base na patronagem e clientelismo, em vez de promoverem formas mais inclusivas de engajamento cívico, portanto deram poder aos ricos deixando os pobres com o capital social. No entanto, como um resultado da crescente influência tanto do neoliberalismo e da metodologia da escolha racional, concepçóes mais radicais e críticas do capital social, como a desenvolvida por Bourdieu, foram descartadas da literatura e da política do Banco Mundial, ou foram reintroduzidas de uma maneira distorcida ao serem reposicionadas em uma posiçáo imperfeita de mercado, compatível com a corrente principal da economia e com a política de terceira via (FINE, 2001 e 2010). 
Essas observações geram ceticismo em relação ao conceito de capital social que ignora condiçôes de conflito e poder e as limitaçôes de grupos paroquiais. A partir disso, Fine se questiona:

Se o conflito mina a noção de capital social, e por que não CONSIDERAR o conflito e seus pressupostos teóricos como um ponto de partida, em vez de um capital social que tem se tronado tanto como ambíguo (se usado para sustentar o poder) e redundante (se ele náo pode superar o poder) (FINE, 2001, p. 123).

Uma resposta a esse tipo de ceticismo deriva de uma série de estudos de casos, os quais foram publicados em um volume especial do Desenvolvimento Mundial e foram conduzidos em regióes menos desenvolvidas do Brasil, Índia, México, Taiwan e Rússia para examinar a relação entre o capital social e o desenvolvimento. Evans (1996a e 1996b), como editor desse volume, encontra evidências de que as redes de uma sinergia entre estado e sociedade podem promover a mobilizaçáo de massa, políticas progressivas e elevados níveis de desenvolvimento de caráter mais programático, redistributivo e compreensivo, inclusive em um ambiente de extrema divergência social, interesses particulares e políticas clientelistas. Esse foi, por exemplo, o caso em Kerala, na Índia (HELLER, 1996). Portanto, em vez de serem os meios para sustentar modos de produçáo opressivos e exploradores e estruturas relacionais, o capital social pode mediar interesses conflituosos para produzir mudanças sociais incorporando os poderes da populaçáo para demandar redistribuição e prover o bem-estar público. A sua luta depende da existência de esferas políticas e sociais para questionar e negociar valores e instituiçóes, para redefinir, por exemplo, o que as pessoas "significam umas às outras", o que elas "podem fazer umas pelas outras" e o que elas são "capazes de fazer umas pelas outras".

No entanto, de acordo com os críticos, uma séria fraqueza nessa literatura parece ser o estabelecimento de uma "pletora de capitais" e um capital fetichista. O capital social é identificado por meio do contraste com outras formas náo sociais de capital, incluindo capital natural, capital físico, capital humano e capital financeiro, o que resulta em um caos de definição em torno não somente do capital, mas também sobre o significado do social. Náo está claro onde o capital tipo físico termina e quando o capital tipo social começa (FINE e LAPAVITSAS, 2003). A partir uma perspectiva Marxista, Fine argumenta que o capital social é um conceito econômico irredutível, que incorpora as relaçóes sociais mais amplas que sustentam estruturas de produção econômica e estratificação social e apoia a subordinação da opressão do trabalho. A partir de então, qualquer uso do termo "capital social”, em seu sentido 
contemporâneo, implica que o capital é um conjunto de doaçôes não sociais o qual é possuído por indivíduos, enquanto o social captura, de uma maneira superficial e supérflua, os resultados econômicos que derivam das características não físicas e não econômicas da sociedade (FINE, 2001). Desse modo, fracassamos em ver o capital como um conjunto de relaçóes exploradoras e autoritárias do capitalismo sobre a classe trabalhadora (FINE e LAPAVITSAS, 2004). No seu trabalho, Fine argumenta que devemos rejeitar o conceito de capital social totalmente e construir uma teoria rigorosa do social, do capital e do capitalismo, construindo nas tradiçôes intelectuais que já temos e apelando a essas noçôes autênticas que são a contrapartida dentro da economia política e da teoria social. Caso contrário, ele argumenta que corremos o risco de criar formas ecléticas ilegítimas, bastardas e sem esperança do social e do capital (FINE, 1999).

Concordamos que o sistema capitalista de produção e a estrutura das relaçôes de poder determinam como o capital social é formado, distribuído e usado para alcançar determinados resultados. Ainda mais no período do Pós-Guerra Fria, apesar do conceito de capital social ter trazido consideraçóes de bem-estar social e do dissenso político, indo além da eficiência econômica, esses significados do conceito foram varridos pelo movimento neoliberal, que prevaleceu em pesquisa e política pública depois do colapso do comunismo Oriental e o aparente triunfo dos sistemas econômicos Ocidentais. Ademais disso, acreditamos que, ao restringir o significado do capital as propriedades de certas perspectivas e sistemas ideológicos, sejam eles neoclássicos ou Marxistas, ignoramos a existência e o potencial de significados alternativos. Da mesma forma, "capital social” pode estar sujeito a muitos significados que vão além de interpretações neoclássicas ou Marxistas. Concepçôes alternativas existem e desafiam as correntes tradicionais de pensamento, focando as circunstâncias políticas e ideológicas sobre as quais os indivíduos desenvolvem e exercitam poder sobre os meios de produção, não somente para preservar relaçóes autoritárias, mas também para garantir a mobilização de massa e o bem-estar público. Mais adiante, examinamos algumas dessas abordagens, onde discutimos o conteúdo de "capital social" dentro de um contexto mais "socializado" ou "socialista".

\section{Capital social de uma perspectiva "socializada" ou "socialista"}

A história do conceito de capital social revela usos alternativos, significados e aplicaçôes alternativas por teóricos sociais, economistas, ativistas e pelos praticantes do desenvolvimento na organização da ação comunitária e movimentos sociais para confrontar as consequências negativas do capitalismo. A ideia do envolvimento e participação em grupos para alcançar o bem-estar individual comunitário foi 
fundamentalmente estabelecida por teóricos sociais dos séculos XVIII e XIX, incluindo Durkheim, Weber e Marx. Influenciados por debates econômicos desse período, eles foram críticos dos utilitaristas e políticos clássicos, como Mill, Bentham e Ricardo, os quais aderiram ao conceito da mão invisível, proposta por Adam Smith, como a última norma para alcançar o bem-estar social dentro da instituiçáo do mercado (WOOLCOCK, 1998; PORTES, 1998; CARROLL e STANFIELD, 2003) ${ }^{1}$. De fato, como aponta Farr, nos seus esforços para desafiar a economia política clássica, alguns críticos já utilizaram o termo capital social para falar do "capital do ponto de vista social" e contrastá-lo com o ponto de vista individual representado por capitalistas e sua busca por lucro (FARR, 2004). Ele observa, entretanto, que o termo se desviou dos tratamentos contemporâneos do capital social e se manifestaram em vários pressupostos e compreensôes conflitivas, a respeito do funcionamento do sistema capitalista, incorporado em uma moldura analítica, tais como o utilitarianismo de Marshall e a teoria do valor-trabalho de Marx.

Para ilustrar, para Marshall, os estoques de capital do ponto de vista social se constituem de um fundo de produção que inclui todas as coisas, exceto a terra (por exemplo, as dádivas naturais da natureza), as quais geram renda e são mantidas para fins de troca, como maquinário, matéria-prima ou bens acabados, teatros e hotéis, casas de fazenda e casas, junto com coisas similares de posse pública, como as indústrias governamentais (MARSHALL, 1997 [1920]). No final do século XIX, Bellamy vê o capital social como a total riqueza acumulada criada pela sociedade por meio de todos os trabalhadores, cujo resultado se direciona para servir às necessidades imediatas de consumo. Isso, de maneira alguma, se relaciona com a concepção de riqueza social quantitativa e calculista de Marshall. Para Bellamy, o capital social é o produto coletivo do "organismo social", por exemplo, de trabalho e intercâmbio, o qual traduz uma visão democrática e igualitária com base na solidariedade e na preservação dos direitos individuais de liberdade, justiça e igualdade, frequentemente violados em um mercado de câmbio não regulado e no capital privado (FARR, 2004). Esse conceito de fundo-social aplicado ao capital social se contrasta com os conceitos de fundos de renda, que se geram em discrepâncias entre os ganhos de renda e mais valia, bem como as condiçôes de subordinação do poder do trabalho aos capitalistas.

\footnotetext{
${ }^{1}$ Devemos perceber que, na Teoria dos Sentimentos Morais, Smith argumenta sobre a confiança do mercado sobre certas sensibilidades morais, entre as quais estáo incluídas a virtude de Sympatheia, um termo filosófico da Grécia Antiga, equivalente à palavra contemporânea inglesa, que vai além do sentimento de gostar do caráter ou companhia de outra pessoa e engloba o ato do compartilhamento dos sentimentos dessa pessoa no azar e na felicidade (SMITH, 1976[1790]).
} 
Alternativamente, o capital social é visto como um produto e propriedade social e propriedade, em oposição às noçóes capitalistas de propriedade privadas e propriedade. Para Marx, capital social está relacionado à noção de agrupamentos agregados de capitais individuais, os quais vão além da soma de recursos físicos, envolvendo a circulação e o capital, bem como a circulação geral de commodities $\left(\right.$ MARX, 1992 [1885])2 ${ }^{2}$ No entanto, ele também fala de um tipo de socialização de capital onde a propriedade privada individualizada, na forma de companhia de açôes e capital financeiro, é inevitavelmente substituída pela propriedade social privada e propriedade. A competição entre capitalistas leva a concentração de capital e o estabelecimento de monopólios, o qual eleva o capital a um poder social geral, enquanto os capitalistas se tornam meros gerentes ou meros capitalistas de dinheiro. Aqui, o capital é associado com a forma de capital social (capital de indivíduos associados indiretamente), em vez de capital privado e a produção privada que ocorre sem o controle da propriedade privada. Isso significa a aboliçáo do modo de produção capitalista e, assim, a autoaboliçãao contraditória onde a autoexpansão do capital, em última análise, apoia a transição a uma nova forma de produção (MARX, 199 [1894]; MARX, 2002 [1857]; LAW e MOONEY, 2006). Recentemente o capital social tem sido associado a noçôes de "posse social" e "propriedade social", que se referem à propriedade produtiva coletiva pertencente pela sociedade ou um grupo, como no caso do grupo de companhias Mondragón na Espanha, assim como em outras cooperativas e sistemas de trabalhadores de autogestão. $\mathrm{O}$ uso e o gerenciamento dos direitos dessa propriedade são exercitados por trabalhadores ou consumidores ou por ambos e são deefindidos, não tanto em termos de títulos legais de propriedade, mas por direitos econômicos para gerenciar e utilizar de tal forma que os benefícios econômicos derivem unicamente do trabalho e não da propriedade (PHILLIPS, 2003).

Adicionalmente, em alguns poucos casos, o capital social tem sido usado para representar um subgrupo de bens de capital que coincide com a infraestrutura pública física de uma nação. Tais definiçóes datam ao final dos anos 1950, quando Dubé, Howes e McQueen definiram capital social como escolas, universidades, igrejas e prédios relacionados, hospitais, estradas e ruas, aeroportos, sistemas de saneamento e de água e outras construçóes em instalaçôes relacionadas a instituiçóes e departamentos públicos de governo. Entretanto, eles argumentam que o capital social

\footnotetext{
${ }^{2}$ Ainda que Marx iguale sociedade civil, um corolário frequentemente citado ao capital social, com a burguesia, Gramsci ignora o determinismo econômico de Marx e argumenta que a sociedade civil é a arena-chave para o conflito e a mudança, ao oferecer o espaço para o desenvolvimento de associaçóes de contra hegemonia (HYDEN, 1997).
} 
não é simplesmente um meio para a organização industrial. Vale a pena considerá-lo como uma expressão de civilização em um sentido elevado (SCHULLER et al., 2000). Da mesma maneira, o capital social e o capital público têm sido usados de forma intercalada nos documentos científicos e governamentais em países como o Japão (ver IHORI e KONDO, 2001). Referências ao capital público como "capital social" quiçá refletem valores que estão imbuídos no governo e na sociedade nesses países e veem a infraestrutura pública não como apenas um meio para promover a indústria, mas também como uma obrigação social e como uma fonte de orgulho nacional, principalmente durante a reconstrução de um país (ver SKOULATOS et al., 2000).

Portanto, existem concepçóes múltiplas e diferenciadas de capital social como um de fundo de capital social, propriedade ou infraestrutura. No entanto, podemos dizer que essas concepçóes geralmente são concomitantes a uma ideia de uma economia socializada com redes densas de associaçóes em uma comunidade, atividades organizadas de trabalho cooperativo e capacidades sociais intensificadas como simpatia e solidariedade, as quais constituem elementos referentes ao capital social em seu sentido contemporâneo (FARR, 2004). O capital social apareceu em seu significado contemporâneo mais amplamente concebido na primeira metade do século XX. Hanifan é frequentemente citado na literatura como a referência pioneira (FARR, 2004). Ele conecta capital social à “ideia de centro comunitário", que inspirou programas de comunidade e educação cívica a confrontarem condiçôes deploráveis de escolas, desigualdades de riqueza e educação, segregação racial, migração e isolamento social. Nas suas palavras, o capital social não se identifica com o tratamento geralmente de capital relacionado a propriedades, propriedade pessoal ou dinheiro. Está associado com aqueles elementos que fazem essas substâncias tangíveis, que valem a pena serem perseguidas (principalmente boa-vontade, companheirismo, simpatia mútua e uma interação social entre indivíduos e famílias sociais) (FARR, 2004). Mais tarde, nos anos 1960, da perspectiva do planejamento urbano e desenvolvimento, Jacobs argumenta que ruas mais seguras e melhores trabalhos dependem do capital social de uma cidade, por exemplo, de confiança entre a vizinhança e redes, em vez de investimentos de subsídios de impostos públicos ou liberdade individual máxima, defendidas por teorias econômicas e de renovação urbana (JACOBS, 1992 [1961]).

Existem pontos de vista que questionam a historicidade do capital social. Para Fine, a história intelectual do capital social é um conto de fadas, pura invenção. Ele afirma que o conto emergiu da microindústria acadêmica que levantou, a partir do seu estado dormente, um número de cientistas sociais relativamente apagados do 
passado e que quase ninguém tinha ouvido deles ou referenciado antes que o capital social ganhasse popularidade nas últimas duas décadas. A ausência do capital social no passado reflete, de acordo com Fine, uma aversão em atrelar a noção de capital social a algo que não fosse econômico (FINE, 2010). Farr argumenta, por outro lado, que a história conceitual do capital social está longe de estar ausente e deveria levar em conta aos escritores do passado em um discurso comum ou (uma) ciência social popular, para assim entender a intenção, contexto, tradição e prospectos expressados ao unir o "social" e o "capital", mesmo nas obras de autores mais proeminentes, como Marx (FARR, 2007).

Além disso, Fine lista uma série de referências que, em sua opiniáo, têm sido negligenciadas na história do capital social e estão relacionadas ao desenvolvimento econômico e ao projeto socialista (FINE, 2010). Separando-se de historiadores tais como Dubé e a contribuição da economia política de Marx, Fine cita as formulaçôes de escritores e representantes do movimento trabalhista na Europa, onde a ideia de capital social pode ser atrelada às demandas da sociedade em relação aos instrumentos de produção. Tais demandas aparecem tanto como propriedade alienável, indivisível e impessoal das massas de trabalhadores, ou como a visão moral da proposta do socialismo contra a pobreza, desemprego, desigualdade e educação precária, ou a força espiritual da poderosa opinião pública contra a plutocracia tirânica. Mesmo que ele acredite que algumas dessas açóes constituíram mais brandas, ou mesmo comprometedoras, em relação a moderar os excessos de posse privada, ele aceita que alguns desses temas que ocorreram ao longo da literatura histórica com explícita referência ao capital social incluem suas distribuições nacional e internacional, posse e controle, sua monopolização e seu impacto nas perspectivas para induzir o aumento de produtividade. Aliás, ele insiste que a única história aceitável do capital social é "aquela onde ele talvez tenha sido traçado de volta ao cavaleiro barbudo com ideias muito diferentes tanto de social como de capital” (FINE, 2010, p. 37).

No todo, apesar do fato de que o capital social tem sido recentemente apropriado por abordagens da corrente econômica, as quais minam o seu escopo analítico na teoria e na prática, uma investigação mais profunda na história conceitual do capital social revela uma série de significados e práticas que salientam o papel dos valores coletivos e as açôes contra as consequências negativas do capitalismo. Não obstante, uma indagação permanece "o que foi especialmente social sobre o social uma coisa com relação ao capital?” (FARR, 2007, p. 55). Talvez, como discute Farr, o uso heurístico de metáforas econômicas, incluindo essa do capital social, foi adotado por um número de movimentos sociais e ativistas em discurso ordinário e ciência social popular para dar ênfase à importância da prospectiva e do fundo 
produtivo criado por trabalho público e compartilhado. Isso não significa que é uma forma de capital que se identifica com suas consequências sociais dentro de um sistema capitalista; na verdade, isso aponta nossa capacidade de identificaçáo das necessidades, aspiraçóes e bem-estar alheios (FARR, 2004 e 2007). De acordo com Dewey, a metáfora do capital é nada mais do que uma estratégia terminológica usada para alcançar efeito crítico e retórico, e para enfatizar a importância de recursos sociais de uma comunidade e bens democráticos de simpatia e cooperação (FARR, 2004).

Ainda, se capital social está para se tornar um heurístico útil em representar as capacidades sociais dos indivíduos para o bem-estar público, então deve se mover para longe de abordagens neoclássicas. Há trabalhos recentes, embora muito limitados por razóes já citadas na Seção "(Des)tratamentos neoclássicos do capital social”, que adotaram uma estância mais radical e apontam restriçóes impostas pelo capitalismo e tornam redes sociais em veículos para a reprodução social de relaçóes capitalistas e estruturas de poder (ver também NAVARRO, 2002; DAS, 2006; IDAHOSA e SHENTON, 2006; MEAGHER, 2006). Dessa maneira, de acordo com Fine, o capital social não apenas se compromete com o liberalismo, mas tem médio alcance à custa do sistêmico e do contextual (FINE, 2010). Contudo, propomos que as redes sociais podem se tornar mediadoras para a mudança social ao formarem pontes entre o intervalo "micro-macro" e ao responderem questóes de como o "indivíduo" interage com o "social" para reavaliar e transformar as estruturas sociais ao alterarem identidades tradicionais e organizarem luta em uma escala maior entre grupos sociais. Exploramos esse potencial introduzindo abordagens alternativas baseadas no conceito de encapsulamento social.

\section{Restaurando o "social" em capital social}

Apesar dos múltiplos significados, a noção de encapsulamento social geralmente enfatiza como as relaçóes econômicas estão entrelaçadas ou enredadas em instituiçóes, ambas econômicas e não econômicas (ÇALIŞKAN e CALLON, 2009). $\mathrm{Na}$ literatura de capital social, Woolcock (1998 e 2002) usa conceitos de "encapsulamento" e "autonomia" para determinar as características das relaçóes sociais que contribuem com o desenvolvimento beneficiário e os resultados do bemestar. Encapsulamento em um nível micro se refere à laços intracomunitários entre indivíduos que constroem coesão entre membros, para realçar sua efetividade em alcançar metas coletivas (ligando capital social), enquanto a autonomia realça a importância de laços intercomunitários, que previnem discriminação e subordinação, a grupos com interesses especiais (criando pontes entre o capital social). Além disso, o 
encapsulamento em nível macro se refere a relações que atravessam a divisão públicoprivada e são forjadas entre organizaçóes privadas - desde atores industriais a associaçóes voluntárias - até decisores públicos (vinculando capital social), enquanto a autonomia é atingida através de melhorias em capacidade institucional e credibilidade. Essa combinação permite aos excluídos não apenas "alcançarem" a comunidade e estabelecer laços e pontes entre os grupos, mas também para escalar os reformadores do Estado e organizaçôes sociais, e influenciarem políticas públicas para a erradicação da pobreza e o enaltecimento de um desenvolvimento amplamente difundido. Woolcock e Narayan (2000) descrevem essa ideia como uma visão sinérgica ao capital social, que integra o trabalho obrigatório que emerge das redes e das abordagens institucionais.

O problema nessa visão é que isso, explicitamente, apela ao trabalho em redes por Granovetter e o trabalho nas instituições por North, e Knack e Keefer, os quais dependem do individualismo e negligenciam a influência de fatores contextuais. Streeck (1998) sugere uma imagem mais complexa do encapsulamento que permite o seguinte: (i) a expressão de uma lógica política de integração social que imporia um sistema de prioridades sociais e obrigaçóes para além da lógica competitiva de eficiência econômica; e, ainda mais importante, (ii) um processo de aprendizado e ressocialização entre partidos que podem levar a uma reestruturação e redefinição de suas identidades, a partir de um partido direcionado por uma monomania econômica a outro que internaliza prioridades sociais, como equidade e justiça, como fins em si mesmos. Não obstante, Streeck (1998) não entende como essa nova ordem social está prestes a ser alcançada através de lutas políticas e reestruturação de identidade particularmente em sociedades caracterizadas pela desigualdade, regimes autoritários, redes de relaçáo patrão-cliente e estruturas hierárquicas. Evans proporciona uma explicação mais detalhada da influência dos obstáculos políticos e sociais ao focar em países menos desenvolvidos. Ele argumenta que, em tais sociedades, a chave real para a sinergia é traduzir laços sociais de mecanismos de lealdades paroquiais para veículos de formas mais englobadas de organização mediante: o fomento da consolidação de organizaçóes sociais representativas e autônomas; gerando uma aliança objetiva entre movimentos sociais e reformistas; fazendo aproveitamento da tradição ativista para uma série mais universal de identidades; e assegurando estruturas de organizaçóes burocráticas baseadas em poderosas normas internas de imparcialidade, transparência e credibilidade (EVANS, 1996b). Para que isso seja atingido, os cidadãos devem se engajar em atividade política para debater os meios e os fins de políticas públicas, para exprimir suas visóes e prever a captura clientelística por parte das elites de laços públicos-privados (EVANS, 1996b; HARRISS, 2002). 
Entretanto, esses estudos não se aprofundam em detalhes sobre a interação entre a agência humana e as estruturas sociais, e o papel desempenhado em moldar e remoldar indivíduos e sociedades. Argumentamos que tal interação é influenciada por um contexto institucional interno no qual os indivíduos estão enraizados e que é caracterizado por variados e frequentes grupos e esferas sociais conflituosos. Seguimos Ponalyi (1944) e adotamos um contexto institucional determinado pela inter-relação entre certas formas de organizaçáo social e integração: trocas promovidas em mercados; redistribuição realizada por estado de bem-estar; e reciprocidade tipicamente relacionada a atividades do setor voluntário. Em qualquer sociedade, formas não mercadistas de redistribuiçáo e reciprocidade poderiam influenciar padróes de comportamento dos indivíduos a mostrarem resistência ao uso de mercado para certos bens e serviços, e evitarem reduzir o valor do comprometimento relacionado à sua provisão (ADAMAN e MADRA, 2002). Polanyi argumenta que a economia está enraizada em relaçóes sociais de tal maneira que o mercado não é o único moldado pelo contexto de vida social; eles são incapazes de operar sem isso: mercados desregulados eventualmente privariam seres humanos e seu ambiente natural da sua entidade moral, psicológica e física. Portanto, à parte de princípios do liberalismo econômico, trocas de mercados pressupóem princípios de proteção social do homem e da natureza, promovidos por instituiçóes de reciprocidade e redistribuição (POLYANI, 1944).

Van Staveren (2001), similarmente sublinha que as capacidades étnicas que pertencem ao domínio de valores de justiça (redistribuição) e cuidado (reciprocidade) são necessárias para a funcionalidade de uma pessoa no domínio da liberdade (troca) e da economia como um todo. Ela propóe um conceito de racionalidade significativa, de acordo com o que atores econômicos investem nas virtudes de cada um dos domínios para competir em troca, concorda com a distribuição legítima e incorpora as necessidades dos contingentes de outros no processo econômico para garantir o bem-estar social. Por exemplo, unióes trabalhistas reclamam por aumentos no somatório total do salário e a produtividade dos trabalhos não pode somente depender da liberdade de perseguir seu autocontentamento; eles deveriam também basear-se em valores de equidade na distribuição de recursos, bem como em valores de simpatia em relação ao interesse geral (VAN STAVEREN, 2001).

Não obstante, existem tensóes que surgem entre diferentes grupos sociais e esferas, determinadas por um conflito de uma pessoa de identidades paroquiais, redes paternalísticas e interesses particularistas (por exemplo, uma mulher que clama por uma posição tanto na esfera pública quanto na privada), assim como a tentativa de outro para organizar e coordenar obrigaçôes conflituosas (a tentativa de uma mulher 
em equilibrar-se em ser mãe, trabalhadora e cidadã). Para resolver essa incomensurabilidade entre múltiplos valores de comprometimento, Van Staveren sugere que agentes poderiam desenvolver várias instituiçôes através do domínio de valores, como a criação de rotinas com significado social e histórico que mediassem os atores em nível médio de interação. Para ilustrar, em um estudo comparativo, Van Staveren observa que tanto em países desenvolvidos como em subdesenvolvidos, mulheres lutam para balancear cuidados em casa, emprego no mercado e participação no discurso político; elas querem ter empregos, mas se preocupam com o compromisso dos cuidados em casa; elas querem cuidar, mas se preocupam quanto ao seu acesso a recursos; e elas querem forçar mudanças políticas, mas se preocupam com sua própria independência no mercado e em casa. Ela argumenta que, longe de se engajar em análises de custo-benefício e gerenciamento de constrangimentos sociais, baseados na teoria da expectativa de utilidades, o presente problema pede por criação de diferentes instituiçóes nos vários domínios de valores de liberdade (mercado), justiça (estado de bem-estar) e cuidados (laços interpessoais), como emprego de meioperíodo, serviços de creche ou licença-maternidade, para combinar múltiplos comprometimentos de maneira significativa (VAN STAVEREN, 2001).

Nesse contexto, o capital social pode ter um papel importante enquanto é construído sob valores de responsabilidade, lealdade, confiança e simpatia, agregados em instituiçóes de relações interpessoais e redes informais, desenvolvidos nos domínios de cuidado, principalmente, de chefes de família, comunidades, associaçóes voluntárias e cooperativas. Instituiçóes de cuidados são cruciais para o domínio de valor da liberdade, porque elas fornecem para os valores sociais as habilidades necessárias para persuadir as partes no mercado a se engajarem em uma troca de benefícios mútuos. Essas instituições também são importantes para o domínio de valor da justiça, porque elas inculcam um senso de lealdade e responsabilidade bem como a ideia compartilhada da necessária interdependência para expressar uma voz comum, construir solidariedade e concordar sobre regras comumente aceitas para redistribuição e equidade no processo econômico (VAN STAVEREN, 2001). Entretanto, alguns casos (estudados) revelam que, em países menos desenvolvidos, especialmente através de redes de micro finanças, a criação de capital social pareceu fomentar formas de associação que agiam conforme normas de gênero e identidades enquanto intensificavam o fardo entre cuidados formal e informal que permaneciam responsabilidade das mulheres (FINE, 2010). Van Staveren nota que instituiçôes de cuidados podem ser constrangedoras, ao passo que redes pessoais podem se tornar paternalísticas e passar por cima de consideraçóes de liberdade individual e equidade social, especialmente quando elas consistem em um número pequeno de pessoas que 
são economicamente influentes. Ela argumenta, no entanto, que instituiçôes podem endogenamente mudar de transformaçóes de valores subjacentes desencadeados por processos de aprendizado e fontes de criatividade. Além disso, mobilizaçáo social e participação política teriam papéis proeminentes nos esforços para acessar e reformular instituiçóes e valores, particularmente nos países menos desenvolvidos onde mulheres enfrentam sérias restriçôes em participar da esfera pública (VAN STAVEREN, 2001). Por último, baseado em evidências proporcionadas por esses estudos de caso, a independência financeira, o avanço educacional e a interação interpessoal que as mulheres obtêm através de participação em redes podem não ser o fim do confronto, mas é definitivamente um começo.

De acordo com Davis, um dos aspectos mais importantes do conceito socialmente enraizado do "si mesmo" é que os indivíduos estão sujeitos à ação humana por meio de sua interaçáo dinâmica com os outros, e, portanto, eles têm a habilidade de agir sob quadros de mudança social (DAVIS, 2003 e 2006b). Ele utiliza a noção de identidade pessoal para enfatizar a capacidade individual em mudança social. Identidade pessoal é definida como o constante esforço do indivíduo em negociar a identidade que está em competição e frequentemente em conflito dada a eles pelas estruturas sociais (DAVIS, 2007). Isso não significa que os indivíduos escolham de um conjunto dado de identidades sociais predeterminadas, como sugere a teoria de maximização utilitária. A noção de Davis sobre identidade pessoal vê o indivíduo como agente reflexivo e autoavaliador que tem a capacidade de revisar e redefinir sua identidade pessoal. $O$ indivíduo reflete e revisa ao avaliar a relaçáo valores-objetivos através de diferentes contextos sociais ou envolvimentos em grupos sociais, e ao agir em sua visão geral e particular sobre como esses valores estão associados com certos tipos de ações em sua parte (DAVIS, 2006b). Além do mais, ocupar uma posição em um grupo social permite aos indivíduos ter o entendimento da organização geral dos grupos dos quais são membros. Isso os habilita a expressar intençôes compartilhadas de como esses grupos funcionam em diferentes aspectos e a se engajarem em avaliar e reavaliar como o grupo é organizado e como as tarefas e direitos são divididas dentro deste. Dessa forma, os indivíduos influenciam as instituiçóes e valores sociais como membros do grupo e a açáo de grupo se torna um interconector intermediário entre ação individual e instituiçôes supraindividuais e valores sociais, esse conector que está ausente das narrativas dominantes da interaçáo humana.

Existem certos fatores que determinam a capacidade de um indivíduo para um comportamento reflexivo e de autoavaliação: consciência do nível individual e a liberdade no nível agregado. Consciência é definida como uma orientação cognitiva 
dos indivíduos em relação a eles mesmos, onde o objeto de orientação interna não é um "si mesmo" preexistente dentro deles, mas várias identidades sociais que eles obtêm em virtude de suas diferentes interaçôes com outros (DAVIS, 2009). Liberdade para perseguir a própria identidade pessoal, como uma capacidade humana básica, depende da existência de sociedades democraticamente abertas que encorajam pluralismo de diferentes pontos de vista e estilos de vida; discussão pública e aberta de assuntos de preocupação comum; e compromisso político e participação em ação pública para a transformação da sociedade (DAVIS e MARIN, 2009). Por fim, dentro de um processo de identidade social em constante mudança, indivíduos dão continuidade e mantém a estabilidade do "si mesmos" de duas maneiras: de um lado, eles reveem preferências, prioridades, emoçôes e deliberaçôes de modo a garantir consistência em seu comprometimento com um conjunto de funcionalidades; por outro lado, eles criam certas instituiçôes sociais, como registros de desempenho educacional, como um meio de suporte social-institucional para facilitar a construção de identidades pessoais (DAVIS, 2009)3.

Isso sugere o que Davis denomina por teoria de intencionalidade coletiva, onde um princípio deontológico de racionalidade baseado em obrigação. Em vez de um princípio instrumental, é usado para explicar as maneiras pelas quais os indivíduos se associam com grupos particulares (DAVIS, 2006a). Sua concepção de identidade reconhece o papel de indivíduos reflexivos e ativos envolvidos em um processo de determinaçáo de seus próprios "si mesmos", contrário aos tratamentos neoclássicos da identidade (FINE, 2009). No entanto, não há nenhuma menção do conteúdo e contexto do funcionamento do conjunto e instituiçôes sociais que os indivíduos criam e se comprometem para construção de sua identidade pessoal. Ele argumenta que os indivíduos determinam suas identidades pessoais ao agir em sua "visão geral", em como valores de diferentes contextos sociais estão associados com certos tipos de açôes empreendidas por eles. Ainda, ele falha em descrever a visão geral que os indivíduos escolhem como ponto de referência para acessar suas múltiplas identidades sociais.

Especulamos que princípios universalmente compartilhados e objetivos que atravessam diferentes grupos e povos existem e poderiam funcionar como um ponto de referência ou um padrão geral contra funcionalidades e instituiçóes que podem ser avaliadas. Em nossa visão, esses princípios universais e objetivos não se identificam

\footnotetext{
${ }^{3}$ Van Staveren e Davis usam o termo "redes" de forma mais franca e optam por termos como "grupos" e "organizaçóes". Apesar de desejarem distância de análises de redes formais, o que tende a aderir a interpretaçôes individualistas de interação humana (ver EMIRBAYER e GOODWIN, 1994).
} 
com experiência pré-cultural ou não histórica baseada em conhecimento específico neutro, nem com uma percepção subjetivista ou relativista de cultura e tradiçáo locais; esses princípios se relacionam com a tarefa de distinção dos elementos que são ampla e profundamente compartilhadas entre os povos e apelam a uma noção de humanidade comum. De acordo com Nussbaum (2002), uma humanidade comum se refere às demandas das necessidades humanas e às frustraçóes da capacidade humana, as quais um indivíduo antecipa e enfrenta, por meio de reflexóes, em qualquer situação ou contexto particular, como experiências de mortalidade e reaçôes do corpo físico, bem como expressões práticas de razão e associação. Para Van Staveren, valores de zelo, sobre os quais o capital social está enraizado, são desenvolvidos na base de necessidades contingentes que surgem da vulnerabilidade humana, e apresentam responsabilidade em relação aos outros e não aderência a um interesse individual ou de grupo (VAN STAVEREN, 2001). Podemos, portanto, estender emoçóes e deliberações de cuidado a um grupo maior de pessoas com as quais, como seres humanos, compartilhamos necessidades em comum por liberdade e justiça. Em outras palavras, isso poderia ser um ponto de partida para criar normas e redes generalizadas de reciprocidade e cooperação que combinam formas de ligaçáo e encapsulamento de capital social e criam o tipo de sinergia que auxilia um amplo desenvolvimento de objetivos de bem-estar.

Além do mais, as várias estruturas sociais dentre das quais os indivíduos estão encapsulados não apenas afetam o conteúdo e o contexto de princípios $\mathrm{e}$ objetivos da ação humana; elas até mesmo podem desafiar a capacidade das pessoas em comportamento reflexivo como no caso de contratos de trabalho exploratório ou a participação limitada das mulheres na esfera pública. Isso significa que aspectos de comportamento ativo e reflexivo deveriam incluir náo somente mudanças na maneira pela qual os indivíduos negociam suas múltiplas identidades sociais, mas também na maneira que ela negocia individual e coletivamente, prevalecendo concepçóes de consciência, liberdade, democracia e autoavaliação. Isso é, além de aspectos de identidade individualmente escolhidos, devemos considerar os significados socialmente construídos que influenciam processos de identidade pessoal ao exercerem restriçóes sobre os esforços das pessoas em fazer escolhas, onde considerem seu senso de si mesmas (FINE, 2009). Por exemplo, uma mulher poderia recusar se ver confinada atrás das barreiras da esfera privada da vida de dona de casa, independente das consequências do isolamento e exclusão. Entretanto, esse tipo de raciocínio só é possível dentro de estruturas sociais onde as mulheres são vistas exclusivamente como esposas e mães ligadas às suas obrigaçóes de casa. Isso não deve ser levado como uma reversão a uma interpretaçâo estruturalista de identidade. 
Aponta, meramente, ao fato de que tal processo não deveria ser restrito à percepção de "si mesmo"; isso deveria se estender a consciência de estruturas sociais. Para o problema, não é meramente uma questão de escolher entre subjetividades alternativas, como mãe, trabalhadora e cidadã. Sobretudo, é algo relacionado a manter o direito de ser um sujeito em vez de um objeto e resistir a grupos sociais dominantes que negam esses direitos às pessoas, através da reestruturação das instituiçóes sociais e valores via mobilização e ação política.

\section{Conclusões}

$\mathrm{Na}$ presente análise, discutimos a identidade do capital social e argumentamos que os modelos econômicos recentes mantêm algumas das suposiçóes centrais da teoria neoclássica convencional, a qual produz uma visão reducionista em relação a açôes de cooperação, confiança, altruísmo e comprometimento. Porém, acreditamos que um termo, que tem sido usado para transmitir noção de capacidades sociais de indivíduos de perseguirem valores compartilhados e objetivos em comum para que o bem-estar social, não caia em descrédito, permanecendo em situação de desdém e no ostracismo do discurso científico com base que tem sido ocupado por paradigmas dominantes com o propósito de expandir sua soberania na sociedade e na economia. Uma investigação mais profunda na história conceitual do capital social revela uma série diversificada de conceitos de definição e contextos analíticos que forneceram uma visão mais socializada, a qual se distancia do individualismo e do neoliberalismo da principal corrente econômica.

Para explorar esse potencial e restaurar a identidade do capital social, apelamos a abordagens alternativas do comportamento humano, baseadas no conceito de encapsulamento social, as quais incluem temas de reflexão, luta política e reestruturação da identidade. Nesse contexto, as necessidades e opinióes dos indivíduos não são restringidas, mas representadas, moldadas e modificadas através de interação e debate. Os valores e objetivos das pessoas não são determinados somente pelas suas consequências, mas servem como seus próprios fins. $\mathrm{O}$ valor da liberdade, que figura proeminentemente na teoria econômica moderna, depende de valores de justiça e zelo que determinem o contexto social das inter-relaçóes dentro as quais trocas livres de mercado serão perseguidas para a proteção social e a conservaçáo do homem, mulher e natureza. Isso é perseguido não somente pela utilidade e eficiência que produz, mas também porque isso é importante por si só, particularmente no desenvolvimento das capacidades individuais que determinam sua identidade pessoal.

Aqui focamos em organizar um quadro geral do comportamento humano para o capital social, algo que pudesse substituir abordagens reducionistas e comuns, 
ao empregarmos noçóes de encapsulamento. Tentamos desenvolver as possibilidades acadêmicas para aplicar racionalidades alternativas e identidades de capital social, as quais estão presentes na história de trabalhos e lutas de teóricos sociais e ativistas que implantaram o conceito de capital social de diversas formas para apontar as consequências negativas do capitalismo, e para a organizaçáo coletiva de modo a perseguir o bem-estar público. Independente se essas possibilidades florescerão e algo a ser visto, de forma que elas serão avaliadas em relação a sua capacidade de contribuir com melhoras em conhecimento e bem-estar. Nessa conjetura, acreditamos que o capital social é útil em revigorar o debate no conteúdo e no contexto do "capital" e do "social". Ao redescobrir e reintroduzir percepçóes alternativas de um modo de vista socializado, podemos reivindicar o conceito de Beckerian e variaçóes do Banco Mundial e evitar o dogmatismo e elitismo de certas abordagens. Isso permitiria mais diversidade e pluralismo, o que refletiria na dinâmica da economia e das sociedades em níveis local e global e verteria luz às possibilidades e condiçóes para construir cooperação, organização de lutas e promoção de mudança social.

Asimina Christoforou é Professora da Athens University of Economics and Business, na Grécia. E-mail: asimina@aueb.gr.

\section{Referências}

ADAMAN, Fikret; MADRA, Yahya M. Theorising the 'third sphere': a critique of the persistence of the 'economistic fallacy'. Journal of Economic Issues, v. 36, n. 4, p. 1045-1078, dez. 2002.

BEBBINGTON, Anthony et al. The Search for Empowerment: Social Capital as Idea and Practice at the World Bank. Bloomfield, USA: Kumarian Press, 2006.

BECKER, Gary Stanley. A theory of social interactions. Journal of Political Economy, v. 82, n. 6, p. 1063-1093, 1974.

BECKER, Gary Stanley. Accounting for Tastes. Cambridge, USA: Harvard University Press, 1996.

BOURDIEU, Pierre. The forms of capital. In: RICHARDSON, John (Ed.). Handbook of Theory and Research for the Sociology of Education. New York: Greenwood Press, 1986. p. 241-58.

BOWLES, Samuel; GINTIS, Herbert. Social capital and community governance. Economic Journal, v. 112, F419-436, nov. 2002.

ÇALIŞKAN, Koray; CALLON, Michel. Economisation, part 1: shifting attention from the economy towards processes of economization. Economy and Society, v. 38, n. 3, p. 369-398, 2009.

CARROLL, Michael C.; STANFIELD, James Ronald. Social capital, Karl Polanyi, and American social and institutional economics. Journal of Economic Issues, v. 37, n. 2, p. 397-404, jun. 2003. 
COLEMAN, James S. Social capital in the creation of human capital. American Journal of Sociology, v. 94, p. S95-S120, 1988.

DAS, Raju J. Putting social capital in its place. Capital and Class, v. 30, n. 6, p. 65-92, 2006.

DAVIS, John B. The Theory of the Individual: Identity and Value. London: Routledge, 2003.

DAVIS, John B. Social identity strategies in recent economics. Journal of Economic Methodology, v. 13, n. 3, p. 371-390, 2006a.

DAVIS, John B. Akerlof and Kranton on identity and economics: inverting the analysis. Cambridge Journal of Economics, v. 31, n. 3, p. 349-362, 2006 b.

DAVIS, John B. Postmodernism and the individual as a process. Review of Social Economy, v. 65, n. 2, p. 203-208, 2007.

DAVIS, John B. Identity and individual economic agents: a narrative approach, Review of Social Economy, v. 67, n. 1, p. 71-94, 2009.

DAVIS, John B.; MARIN, Solange Regina. Identity and democracy: linking individual and social reasoning. Development, v. 52, n. 4, 500-508, 2009.

EDWARDS, Bob; FOLEY, Michael W. Civil society and social capital beyond Putnam. American Behavioral Scientist, v. 42, n. 1, p. 124-139, 1998.

EMIRBAYER, Mustafa; GOODWIN, Jeff. Network analysis, culture, and the problem of agency. American Journal of Sociology, v. 99, n. 6, p. 1411-1454, maio 1994.

EVANS, Peter. Introduction: development strategies across the public-private divide. World Development, v. 24, n. 6, p. 1033-1037, jun. 1996a.

EVANS, Peter. Government action, social capital and development: reviewing the evidence on synergy. World Development, v. 24, n. 6, p. 1119-1132, fev. 1996 b.

FARR, James. Social capital: a conceptual history. Political Theory, v. 32, n. 1, p. 6-33, fev. 2004.

FARR, James. In search of social capital: a reply to Ben Fine. Political Theory, v. 35, n. 1, p. 54-61, fev. 2007.

FINE, Ben. The developmental state is dead - long live social capital? Development and Change, v. 30, n. 1, p. 1-19, jan. 1999.

FINE, Ben. Social Capital vs. Social Theory: Political Economy and Social Science at the Turn of the Millennium. London: Routledge, 2001.

FINE, Ben. It ain't social, it ain't capital and it ain't Africa. Studia Africana, v. 13, p. 18-33, 2002.

FINE, Ben. The economics of identity and the identity of economics? Cambridge Journal of Economics, v. 33, n. 2, p. 175-91, 2009.

FINE, Ben. Theories of Social Capital: Researchers Behaving Badly. London: Pluto Press, 2010.

FINE, Ben; LAPAVITSAS, Costas. Social capital and capitalist economies. South Eastern Europe Journal of Economics, v. 1, p. 17-34, 2004.

GLAESER, Edward L. et al. What is Social Capital? The Determinants of Trust and Trustworthiness. National Bureau of Economic Research, n. 7216, jul. 1999.

GLAESER, Edward L. et al. An economic approach to social capital. Economic Journal, v. 112, p. F437-458, nov. 2002.

HARRISS, John. Depoliticising Development: The World Bank and Social Capital. London: Anthem Press, 2002.

HELLER, P. Social capital as a product of class mobilisation and state intervention: industrial workers in Kerala, India. World Development, v. 24, n. 6, p. 1055-1071, jun. 1996. 
HYDEN, Goran. Civil society, social capital, and development: dissection of a complex discourse. Studies in Comparative International Development, v. 32, n. 1, p. 3-30, 1997.

IDAHOSA, Pablo; SHENTON, Bob. The layers of social capital. African Studies, v. 65, n. 1, p. 6378, jul. 2006.

IHORI, Toshihiro; KONDO, Hiroki. Efficiency of disaggregate public capital provision in Japan. Public Finance and Management, v. 1, n. 2, 161-182. 2001.

JACOBS, Jane. The Death and Life of Great American Cities. New York: Vintage Books, 1992 [1961].

LAW, Alex; MOONEY, Gerry. The maladies of social capital I: the missing 'capital' in theories of social capital. Critique, v. 34, n. 2, p. 127-143, 2006.

LOURY, Glenn C. A dynamic theory of racial income differences. In: WALLACE, Phyllis Ann; LEMUND, Annette (Eds). Women, Minorities, and Employment Discrimination. Lexington, USA: Lexington Books, 1977. p. 153-86.

LOURY, Glenn C. Why should we care about group inequality? Social Philosophy and Policy, v. 5, n. 1, p. 249-271, 1987.

MARSHALL, Alfred. Principles of Economics. New York: Prometheus Books, 1997 [1920].

MARX, Karl. Capital: A Critique of Political Economy, vol. 3. London: Penguin Books, 1991 [1894].

MARX, Karl. Capital: A Critique of Political Economy, vol. 2. London: Penguin Books, 1992 [1885].

MARX, Karl. Grundrisse: Outlines of the Critique of Political Economy. 2002 [1857]. Disponível em: <http://www.marxists.org/archive/marx/works/1857/grundrisse/>. Acesso em: 14 jul 2009.

MEAGHER, Kate. Social capital, social liabilities, and political capital: social networks and informal manufacturing in Nigeria. African Affairs, v. 105, p. 553-582, 2006.

NAVARRO, Vicente. A critique of social capital. International Journal of Health Services, v. 32, n. 3, p. 423-432, 2002.

NUSSBAUM, Martha C. Non-relative virtues: an Aristotelian approach. In: NUSSBAUM, Martha C.; SEN, Amartya (Eds.). The Quality of Life. Oxford: Oxford University Press, 2002. p. 242-69.

PHILLIPS, Paul. Social ownership and property. In: O'HARA, Phillip Anthony (Ed.). Encyclopedia of Political Economy. London: Routledge, 2003. p. 1051-54.

POLANYI, Karl. The Great Transformation. New York: Amereon House, 1944.

PORTES, Alejandro. Social capital: its origins and applications in modern sociology. Annual Review of Sociology, v. 24, 1-24, ago. 1998.

PUTNAM, Robert D. Making Democracy Work: Civic Traditions in Modern Italy. Princeton: Princeton University Press. 1993.

SCHULLER, Tom et al. Social capital: a review and critique. In: BARON, Stephen; FIELD, John; SCHUlLER, Tom. (Eds.). Social Capital: Critical Perspectives. Oxford: Oxford University Press, 2000. p. 1-38.

SCHUURMAN, Frans J. Social capital: the politico-emancipatory potential of a disputed concept. Third World Quarterly, v. 24, n. 6, p. 991-1010, 2003.

SKOUlATOS, V. et al. Modern History - 3rd Grade Lyceum, v. C. Athens: Organisation for Publication of School Textbooks (in Greek), 2000.

SMITH, Adam. The Theory of Moral Sentiments. Oxford: Clarendon Press, 1976 [1790].

SMITH, Stephen Samuel; KULYNYCH, Jessica. It may be social, but why is it capital? The social construction of social capital and the politics of language. Politics \& Society, v. 30, n. 1, p. 149-186, mar. 2002. 
STREECK, Wolfgang. Beneficial constraints: on the economic limits of rational voluntarism. In: HOLLINGSWORTH, J. Rogers; BOYER, Robert (Eds.). Contemporary Capitalism: The Embeddedness of Institutions. Cambridge, UK: Cambridge University Press, 1998. p. 197-219.

VAN STAVEREN, Irene. The Values of Economics: An Aristotelian Perspective. London: Routledge. 2001.

WOOLCOCK, Michael. Social capital and economic development: toward a theoretical synthesis and policy framework. Theory and Society, v. 72, n. 2, p. 151-208, 1998.

WOOLCOCK, Michael. Social capital in theory and practice: where do we stand? In: ISHAM, Jonathan; KELLY, Thomas; RAMASWAMY, Sunder (Eds). Social Capital and Economic Development: Wellbeing in Developing Countries. Cheltenham, UK: Edward Elgar, 2002. p. 18-39. WOOLCOCK, Michael; NARAYAN, Deepa. Social capital: implications for development theory, research, and policy. World Bank Research Observer, v. 15, n. 2, p. 225-249, 2000.

\section{Publicado originalmente como:}

CHRISTOFOROU, Asimina. On the identity of social capital and the social capital of identity. Cambridge Journal of Economics, v. 37, n. 4, p. 719-736. 2013.

Publicação autorizada pela Oxford University Press. Data de Licença 21 de novembro de 2014. Número de Licença 3513810656296.

Texto recebido em 22 de maio de 2015. Aprovado em 03 de agosto de 2015. 
